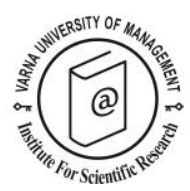

\title{
Davis, A. and Smeds, K. (Eds.) (2016). Visiting the Visitor: \\ An Enquiry into the Visitor Business in Museums, \\ Transcript Verlag, 2016, 250 pp. ISBN: 978-3-8376-3289-7.
}

\author{
Reviewed by Illkay Taş Gürsoy ${ }^{1}$
}

Received: 18/01/2018

1 Midilli Foça Faculty of Tourism, Dokuz Eylül Üniversity, Turkey: email: ilkay.tas@deu.edu.tr, ilkay2008@yahoo.com

(C) 2018 Varna University of Management. All rights reserved

Citation Davis, A. and Smeds, K. (Eds.) (2016). Visiting the Visitor: An Enquiry into the Visitor Business in Museums, Transcript Verlag, 2016, 250 pp. ISBN: 978-3-8376-3289-7. Reviewed by İlkay Taş Gürsoy, European Journal of Tourism Research 19, pp. 154-155

Visiting the Visitor: An Enquiry into the Visitor Business in Museums is a timely contribution to the scholarship on visitor experience as tourism and leisure research looks for innovative ways to explore multiple perspectives in visitor business. Visiting the Visitor, edited by Ann Davis and Kerstin Smeds is a collection of contributions of 14 authors where the editors, Davis and Smeds, contribute to the volume as authors too. The short bios of the authors given at the end of the volume are impressive in terms of the richness and transnationality of authors' academic experience. This is a 15-chapter volume which brings scholars with various academic interests together ranging from museology and heritage management to cognitive studies, marketing and modern rhetorical theory. Although chapters are not given numbers in the volume, perhaps for not interrupting the narrative of the volume with numerical signs, for the sake of a structured follow-up, I will mention them in numbers according to their sequence in the content of the volume.
The volume starts with an Introduction where the editors involve the readers into the debate by making them question how to gain access to the visitor experience. In the introduction part, the editors explain the rationale of the book and provide insight for the remainder of the volume. This, in a way, can be likened to the entrance hall of a museum where you get a clue of what to expect inside but never know exactly what/how to see and how this would influence you. The chapters are like the exhibition halls of a museum in that they introduce readers to different aspects of visitor/ museum/visiting business. As readers move throughout the book, they visit the intellectual/imaginary space created for them across the chapters.

Chapter 1, by Jennifer Harris, questions the role of affect in exhibition-visits. Having set the theoretical ground for affect and having discussed about private and social relations, Harris guides the readers/visitors to three museum spaces. In chapter 2, M. Elizabeth Weiser, meticulously draws the readers' 
Davis, A. and Smeds, K. (Eds.) (2016). Visiting the Visitor: An Enquiry into the Visitor Business in Museums, Transcript Verlag, 2016, 250 pp. ISBN: 978-3-8376-3289-7. Reviewed by İlkay Taş Gürsoy,

European Journal of Tourism Research 19, pp. 154-155

attention to the nexus of individual identity and collective history by depicting lively accounts of museum spaces under the theoretical insight of modern rhetorical theorist Kenneth Burke. In chapter 3, Daniel Schmitt turns on the light of semiological theory of the course-of-experience for understanding visitor experience. Chapter 4, by John Falk, focuses on the role of identity in creation and understanding of museum experience and proposes a new model including identity-related motivations. In chapter 5 Ann Davis, having derived from the remarks of Falk, takes the debate to social aspects of museum visits. Davis discusses motivational factors, market forces and offers new ways of looking at the role of museums for empowering visitors.

Kerstin Smeds, in chapter 6, starts with a question: "Is the mankind on decline?". While you try to figure out an answer, Smeds takes your attention back to visitor business by referring to two contending views: freedom/right of individuals to access to heritage items on one hand and the obligation to protect them from everybody on the other. In this regard, Smeds provides a phenomenological assessment of individualmuseum interaction by analysing institutional and individual aspects of museum settings. Bruno Brulon Soares, in chapter 7, introduces the readers to the scenes "behind the curtains of museum performance". By an analogy between museums and theaters, Soares narrates an interesting account of museum visit as theatrical performance. Aida Rechena, in chapter 8, takes this lively depiction one step further by adding insight of social representational theory into understanding of visitor behaviour. In chapter 9, Anna Leshchenko, uses perceptual theory as a tool and delves into perceptual issues at museum spaces. Leshchenko posits ways of enriching museum experience with physical senses.

Vitaly Ananiev, contributes to the volume by two subsequent chapters (chapter 10 and 11). Ananiev, firstly, discusses the concept of dialog developed by philosopher Mikhail
Bakhtin and brings the theory of mirror neurons into the debate about visitor-museum interaction. Ananiev, then, continues to elaborate on the visitor studies by analysing historical and contemporary contexts and by sharing an example from Russian experience. Žarka Vujić and Helena Stublić, in chapter 12, take readers to another geographical area and to another time, namely to Socialist Croatia. The authors provide interesting details about visitor empowerment in this period. Museum refurbishment, an aspect of museum performance, is the topic of sophisticated analysis by Maria Cristina Vannini in terms of identity and authenticity, in chapter 13. Wan-Chen Chang, in chapter 14, continues to address the issue of authenticity in museum experience by examining a case study from Taiwan. The last chapter, by Colette Dufresne-Tassé is devoted to exploring power relationship between museum and its visitors. Dufresne-Tassé presents the thought provoking results which her research team have found regarding the extent of power sharing in museum space.

The volume has made quite an impression on me regarding its solid theoretical base and lively depictions of museum spaces with examples taken from various countries. Each chapter gives a fresh voice to the debate by presenting a different theoretical perspective on institutional, personal and/or practical aspects of visitor/ visiting experience. While answering a lot about visitor experience, the volume plants new questions and new ideas for further research in the minds of readers. However, a drawback would be lack of an afterword which would provide an integrating ground for such a comprehensive volume. Regarding its scope and depth, this volume can be suggested as a textbook for graduate students and researchers interested in culture, tourism and leisure. I also believe that readers who are not necessarily involved in a related study area but enjoy reflexive thinking about experiencing social life will find the volume interesting as it sets to explore meaning of experience as a visitor. 